\title{
Management of mydriasis and pain in cataract and intraocular lens surgery: review of current medications and future directions
}

This article was published in the following Dove Press journal:

Clinical Ophthalmology

3 July 2014

Number of times this article has been viewed

\author{
Seanna R Grob ${ }^{1-3}$ \\ Luis A Gonzalez- \\ Gonzalez ${ }^{1-3}$ \\ Mary K Daly $1,2,4$
}

'Department of Ophthalmology, Veterans Administration Boston Healthcare System, Boston, MA, USA; ${ }^{2}$ Department of Ophthalmology, Harvard Medical School, Boston, MA, USA; ${ }^{3}$ Department of Ophthalmology, Massachusetts Eye and Ear Infirmary, Boston, MA, USA; ${ }^{4}$ Department of Ophthalmology, Boston University School of Medicine, Boston, MA, USA
Correspondence: Mary Daly Veterans Administration Boston Healthcare System, Jamaica Plain, Boston, MA, USA

Tel +l 8573644635

Fax +l 8573644407

Email mary.daly2@va.gov
Abstract: The maintenance of mydriasis and the control of postoperative pain and inflammation are critical to the safety and success of cataract and intraocular lens replacement surgery. Appropriate mydriasis is usually achieved by topical and/or intracameral administration of anticholinergic agents, sympathomimetic agents, or both, with the most commonly used being cyclopentolate, tropicamide, and phenylephrine. Ocular inflammation is common after cataract surgery. Topical steroids and nonsteroidal anti-inflammatory drugs are widely used because they have been proved effective to control postsurgical inflammation and decrease pain. Topical nonsteroidal anti-inflammatory drugs have also been shown to help maintain dilation. However, use of multiple preoperative drops for pupil dilation, inflammation, and pain control have been shown to be time consuming, resulting in delays to the operating room, and they cause dissatisfaction among perioperative personnel; their use can also be associated with systemic side effects. Therefore, ophthalmologists have been in search of new options to streamline this process. This article will review the current medications commonly used for intraoperative mydriasis, as well as pain and inflammation control. In addition, a new combination of ketorolac, an anti-inflammatory agent, and phenylephrine, a mydriatic agent has recently been designed to maintain intraoperative mydriasis and to reduce postoperative pain and irritation from intraocular lens replacement surgery. Two Phase III clinical trials evaluating this combination have demonstrated statistically significant differences when compared to placebo in maintaining intraoperative mydriasis $(P<0.00001)$ and in reducing pain in the early postoperative period ( $P=0.0002$ ). This medication may be of benefit for use in cataract and lens replacement surgery in the near future.

Keywords: ketorolac, phenylephrine, intraocular lens replacement surgery, mydriasis

\section{Introduction}

Appropriate mydriasis and inflammatory control during intraocular lens (IOL) exchange surgery is key to a successful surgical outcome. ${ }^{1,2}$ To achieve these aims, a myriad of topical and/or intracameral agents have been used to dilate the pupil and to control postoperative pain and inflammation. Therefore, ophthalmologists have been in search of new options to streamline the process of intraoperative mydriasis and to treat postoperative inflammation. These new therapies include a combination of ketorolac, an anti-inflammatory agent, and phenylephrine, a mydriatic agent. Ketorolac acts as a nonselective cyclooxygenase (COX)-1/COX-2 inhibitor, ${ }^{3,4}$ and phenylephrine as an alpha-1 adrenergic receptor agonist. ${ }^{5,6}$ These compounds have shown effectiveness in controlling postoperative pain and inflammation and in the maintenance of mydriasis during surgery, respectively. ${ }^{6-10}$ Ketorolac has also shown beneficial effects in the maintenance of intraoperative mydriasis; however, there is no consensus on its use as a 
primary mydriatic agent in ophthalmic surgery. ${ }^{11} \mathrm{OMS} 302$ is a new product developed by Omeros Corporation (Seattle, WA, USA), proprietary PharmacoSurgery ${ }^{\mathrm{TM}}$, that is targeted for use during IOL replacement (ILR) surgery, which includes cataract surgery and refractive lens exchange. ${ }^{12}$ (None of the authors have or have had any current or past financial interest, support or research participation in Omeros Corporation). The OMS302 combination is designed to maintain intraoperative mydriasis and reduce postoperative pain and inflammation resulting from ILR surgery.

ILR surgery involves replacement of the original lens of the eye with an artificial IOL. This procedure is typically performed to treat cataracts or to correct a refractive error (ie, refractive lens exchange). ${ }^{13-15}$ Maintenance of mydriasis is critical to the safety and surgical ease of the procedure. ${ }^{16}$ Intraoperative pupil constriction is associated with an increased risk of intraoperative complications, especially in difficult cases, and it can result in prolonged surgical time. ${ }^{17,18}$ In addition, the prevention of postoperative pain can improve patient satisfaction with the surgery and the surgeon. ${ }^{19}$ OMS302 may be added to a standard irrigation solution used in ILR surgery and it can be delivered intracamerally to maintain mydriasis, to prevent miosis, and to reduce postoperative pain and inflammation. ${ }^{3}$

We will discuss the current status of ILR surgery including the available methods for intraoperative maintenance of mydriasis and the control of postoperative pain and inflammation. Then, we will review the progress and available data from the clinical research trials evaluating OMS302.

\section{IOL replacement surgery Epidemiology}

Approximately $30 \%$ of the population over 65 years of age in the UK has visually significant cataracts. ${ }^{20,21}$ An estimated $17.2 \%$ of the United States population, or approximately 20.5 million people over the age of 40 years, will have a cataract in either eye. ${ }^{20,22} \mathrm{By} 2020$, this number in the US is expected to rise even further to 30.1 million. ${ }^{22}$ Currently, cataracts are responsible for approximately $60 \%$ of Medicare costs associated with vision care. ${ }^{20}$ There are an estimated 3.6 million ILR procedures expected in the US this year, and 15 million in developed countries, with a projected annual growth rate of 3\%-4\%. ${ }^{3}$ Most commonly, the indication for ILR surgery is cataract extraction, although refractive lens exchange is a growing segment of the lens replacement market. ${ }^{13-15}$ The most frequent indications for removing and replacing a current IOL are IOL dislocation/decentration, incorrect IOL power, glare/optical aberrations, and IOL calcification..$^{23-27}$

\section{Difficulties/complications of IOL replacement surgery \\ Mydriasis in cataract surgery}

Appropriate mydriasis during IOL exchange surgery is key to a successful surgical outcome. ${ }^{1}$ Impaired visualization through a small pupil increases the chance of tissue damage, retained nuclear material, and vitreous loss. ${ }^{17,18}$ Currently, dilation is achieved by topical and/or intracameral administration of anticholinergic agents, sympathomimetic agents, or both, with the most commonly used being cyclopentolate, tropicamide, and phenylephrine. ${ }^{28-31}$ Topical mydriatic agents have been used for many years to dilate the pupil before cataract surgery. However, the use of multiple preoperative drops for pupil dilation was shown to be inexact, and this could delay surgery, and cause dissatisfaction among perioperative personnel; moreover, their use is also associated with systemic side effects. ${ }^{28,29}$ Adverse ocular and systemic side effects make their use in high-risk patients (for example, hypertensive or elderly patients and children) more of a concern. ${ }^{30,31}$ Therefore, ophthalmologists have been in search of new options to streamline the process of intraoperative mydriasis. Available mydriatic agents and their side effects are summarized in Table 1.

\section{Postoperative pain and inflammation}

Ocular inflammation is common after cataract surgery. Untreated inflammation may cause pain, photophobia, and

Table I Mydriatic agents for lens replacement surgery

\begin{tabular}{|c|c|c|c|}
\hline Medication & Mechanism of dilation & Formulations & Side effects \\
\hline Phenylephrine & Acts on the iris dilator muscle & $2.5 \%, 5 \%, 10 \%$ & $\begin{array}{l}\text { Hypertension, syncope, myocardial infarction, } \\
\text { tachycardia, and arrhythmia }\end{array}$ \\
\hline Tropicamide & Relaxation of the pupillary sphincter & $0.5 \%, 1.0 \%$ & $\begin{array}{l}\text { Dry mouth, tachycardia, headache, and allergic } \\
\text { reactions }\end{array}$ \\
\hline Cyclopentolate & $\begin{array}{l}\text { Blocks contraction of the pupillary } \\
\text { sphincter muscle }\end{array}$ & $0.5 \%, 1.0 \%, 2.0 \%$ & $\begin{array}{l}\text { Disorientation, dry mouth, incoherent speech, } \\
\text { or visual disturbances }\end{array}$ \\
\hline Atropine & $\begin{array}{l}\text { Blocks contraction of the pupillary } \\
\text { sphincter muscle }\end{array}$ & $0.5 \%, 1.0 \%$ & $\begin{array}{l}\text { Dry mouth, confusion, ventricular fibrillation, } \\
\text { tachycardia, and nausea }\end{array}$ \\
\hline
\end{tabular}


other complications such as increased intraocular pressure, posterior capsule opacification, and cystoid macular edema. ${ }^{32}$ Topical steroid therapy has been used for many years to control perioperative and postoperative inflammation, but it may inhibit corneal wound healing, increase intraocular pressure, increase the likelihood of infection, and lead to other serious complications. ${ }^{7,33-35}$ Topical nonsteroidal anti-inflammatory drugs (NSAIDs) are widely used because they have been proven effective in the control of postsurgical inflammation without the risks of steroid-related side effects. ${ }^{7,34,36,37}$ Preoperative treatment with NSAIDs, followed by combined therapy with NSAIDs and steroids postoperatively, has become the standard of care. ${ }^{36,38}$

\section{Use of analgesic/mydriatic agents in IOL replacement surgery \\ Topical}

Pharmacologic mydriasis can be achieved using a number of different topical agents. Phenylephrine is an adrenergic stimulant that acts on the iris dilator muscle. Its mydriatic effects have been known for some time., ${ }^{9,39,40}$ There are different concentrations of phenylephrine and some studies have shown an increase in the effectiveness of dilation at higher concentrations. ${ }^{10,42}$ However, higher concentrations have also been associated with more systemic side effects. ${ }^{30,41-43}$ Side effects are mostly cardiovascular reactions, primarily seen in the high-risk populations such as among the elderly, hypertensive patients, and children, and these effects include a marked increase in blood pressure, myocardial infarction, arrhythmia, syncope, and tachycardia. ${ }^{44}$

Acetylcholine antagonists, such as tropicamide, allow for relaxation of the iris sphincter. ${ }^{45}$ A common regimen for cataract surgery, as mentioned previously, includes phenylephrine and tropicamide with or without cyclopentolate. Topical tropicamide has been shown to cause nonocular reactions including dry mouth, allergic reactions, headache, and tachycardia. ${ }^{44,46}$ Other muscarinic antagonists include cyclopentolate and atropine. Atropine is not as regularly used due to its long-lasting effects and given that evidence shows that there is not an increase in the mydriatic effect with the addition of atropine to the standard regimens. ${ }^{47}$

A new topical ocular insert, Mydriasert ${ }^{\circledR}$ (Spectrum Thea Pharmaceuticals Limited, Cheshire, UK) has also been evaluated for its efficacy and safety in its use for cataract surgery. ${ }^{48}$ It is a small, oblong, cylinder-shaped insert that includes $0.28 \mathrm{mg}$ of tropicamide and $5.4 \mathrm{mg}$ of phenylephrine hydrochloride. It is placed in the inferior fornix of the eye undergoing surgery. There was no statistically significant difference in the pupil diameter during surgery in patients using Mydriasert ${ }^{\circledR}$ versus those who received conventional topical dilating eye drops (tropicamide 1\%, phenylephrine 10\%, and cyclopentolate $1 \%) .{ }^{48}$ However, pupil size was restored to normal much more quickly (when evaluated at 24 hours) with Mydriasert ${ }^{\circledR}$ compared to conventional therapy. This effect is likely related to the lack of cyclopentolate in the insert, which is known for its long-lasting pupillary effects. ${ }^{48}$ Importantly, this insert needs to be in place 60 minutes prior to surgery; however, it does provide the advantage of not having to instill multiple rounds of eye drops. ${ }^{48}$

The preoperative use of NSAIDs has also been shown to be effective in maintaining mydriasis during cataract surgery. ${ }^{1}$ Miosis during cataract surgery is thought to be partly related to an increase in the concentration of prostaglandins. ${ }^{49}$ NSAIDs work by their ability to inhibit COX, which ultimately decreases the production of prostaglandins. ${ }^{50}$ In addition, steroids are known to block the release of arachidonic acid, which is also a precursor for prostaglandin synthesis. ${ }^{51}$ Options include, but are not limited to, ketorolac, nepafenac, flurbifrofen, and prednisolone. There is evidence that preoperative NSAIDs and/or steroid drops are effective in maintaining intraoperative mydriasis as compared to no other additional preoperative eye drops. ${ }^{1,52,53}$

Additionally, both NSAIDs and steroids are included in many perioperative drop regimens. Often, patients are maintained on an NSAID and a steroid drop for 2-4 weeks after cataract surgery for postoperative inflammation and pain control..$^{51}$ Nepafenac, a topical NSAID, is often used starting 1 day prior to cataract surgery and continued for the first 2 weeks in the postoperative period. It is an inhibitor of COX-1/COX-2 and has shown efficacy in controlling pain and inflammation associated with cataract surgery. ${ }^{54-56}$ Normally, the nepafenac $0.1 \%$ ophthalmic suspension is used three times daily; however, a new once-daily $0.3 \%$ formulation has been shown to be noninferior to nepafenac $0.1 \%$ in controlling inflammation and pain. ${ }^{57}$ Other available NSAIDs are presented in Table 2.

\section{Intracameral mydriatics}

Intracameral mydriatics were introduced in 2003, and the original compound included a preservative-free mixture of cyclopentolate $0.1 \%$, phenylephrine $1.5 \%$, and lidocaine $1 \% .{ }^{29}$ Cyclopentolate later demonstrated no additional mydriatic effects to phenylephrine $1.5 \%$ when administered together with lidocaine. ${ }^{58}$ It has also been established that the addition of epinephrine to the 
Table 2 Available nonsteroidal anti-inflammatory drugs

\begin{tabular}{|c|c|c|c|}
\hline Drug & Formulations & Preparation & FDA approved \\
\hline Indomethacin & $1 \%$ & Indole & Available outside of the US \\
\hline Flurbiprofen & $0.03 \%$ & Water-soluble phenylalkanoic acid & $\begin{array}{l}\text { Approved for intraoperative use during cataract surgery } \\
\text { for the inhibition of miosis }\end{array}$ \\
\hline Suprofen & $1 \%$ & Water-soluble phenylalkanoic acid & $\begin{array}{l}\text { Approved for intraoperative use during cataract surgery } \\
\text { for the inhibition of miosis }\end{array}$ \\
\hline Ketorolac tromethamine & $0.5 \%$ & Water-soluble phenylalkanoic acid & Postoperative inflammation and pain control \\
\hline Diclofenac & $1 \%$ & Water-soluble phenylalkanoic acid & Minimize inflammation related to cataract surgery \\
\hline Bromfenac & $0.09 \%$ & Water-soluble phenylalkanoic acid & Postoperative inflammation \\
\hline Nepafenac & $0.1 \%$ & Prodrug arylacetic acid & Pain and inflammation associated with cataract surgery \\
\hline
\end{tabular}

Abbreviation: FDA, Food and Drug Administration.

irrigating solution is not necessary when intracameral mydriatics are being used..$^{59}$ Intracameral mydriatics have been shown to provide sufficient pupil dilation without causing measurable ocular side effects or influencing the phacoemulsification procedure negatively, as compared to topical mydriatics. ${ }^{29,60,61}$

One of the early randomized, controlled studies of intracameral injections ${ }^{29}$ evaluated 60 patients who received either intracameral injection of mydriatics in phacoemulsification cataract surgery versus conventional topical therapy. One group received topical mydriatics comprised of three drops of cyclopentolate $1 \%$ and phenylephrine $1 \%$, which were given 15 minutes apart, and $150 \mu \mathrm{L}$ of intracameral lidocaine hydrochloride $1 \%$. The other group received intracameral mydriatics including $150 \mu \mathrm{L}$ of cyclopentolate $0.1 \%$, phenylephrine $1.5 \%$, and lidocaine hydrochloride $1 \%$ with placebo eye drops. The patients with intracameral mydriatics achieved rapid results with $95 \% \pm 3 \%$ (standard deviation) of the final value of mydriasis within 20 seconds. Intracameral mydriatics were effective and safe as well. However, the pupils tended to be slightly smaller than in the topical group (mean $6.7 \pm 1.0 \mathrm{~mm}$ versus $7.7 \pm 1.0 \mathrm{~mm} ; P<0.001$ ), but the pupils did not contract intraoperatively.

Over time, other intracameral combinations were studied, and it was found that similar levels of effectiveness could be achieved with fewer medications in the formulation. ${ }^{29,60,61}$ A study evaluated intraoperative mydriasis in 31 consecutive eyes scheduled for phacoemulsification cataract extraction and IOL implantation using an intracameral injection of $0.2-0.3 \mathrm{~mL}$ of preservative-free $1 \%$ lidocaine without any additional preoperative or intraoperative mydriatics. ${ }^{62}$ The mean pupil diameter after intracameral lidocaine was significantly greater than the baseline pupil size, and it increased by $4.39 \pm 0.53 \mathrm{~mm}$. The pupil dilation was found to be satisfactory, persistent, and stable throughout the duration of the cataract surgery. ${ }^{62}$ Previously, Cionni et al ${ }^{63}$ used lidocaine $1 \%$ as a single intracameral mydriatic agent with the addition of epinephrine to the irrigation fluid, and it showed adequate dilation for cataract surgery in 12 patients.

Intracameral lidocaine has also been shown to relieve intraoperative discomfort related to iris movement or manipulation. ${ }^{64,65}$ The amount of $0.1-0.5 \mathrm{~mL}$ of unpreserved lidocaine can be injected into the anterior chamber for intraoperative pain control. Combined topical and intracameral anesthesia is well tolerated and it is effective in maintaining a low pain score during cataract surgery in most patients (approximately $76 \%$ of patients). ${ }^{66}$ Intracameral triamcinolone acetonide has also shown effectiveness in the prevention of postoperative anterior chamber inflammation in patients undergoing phacoemulsification ${ }^{67}$ and phacotrabeculectomy. ${ }^{67,68}$

The intracameral method has also been suggested to improve the operating conditions in more complicated cataract surgeries, including those with intraoperative floppy iris syndrome, by stabilizing the iris during surgery ${ }^{69-72} \mathrm{~A}$ recent study ${ }^{72}$ evaluated the efficacy of intracameral phenylephrine on 42 patients receiving tamsulosin and undergoing cataract surgery. Intracameral phenylephrine was found to be highly effective for prophylaxis of floppy iris syndrome by reversing intraoperative floppy iris, restoring iris rigidity and causing the pupil to return to its normal preoperative size. ${ }^{72}$

\section{Mechanical}

If the necessary pupil dilation cannot be achieved with medications alone, then alternative mechanical devices are available for dilation assistance. The next step in pupil dilation involves mechanical stretching of the pupil. ${ }^{73}$ Other options include iris retainers, which are devices developed to hold the iris in an enlarged state, or physical cutting of the iris sphincter. ${ }^{73}$ Adjunct devices for pupil expansion include nylon iris hooks, the Beehler pupil dilator (MORIA SA, Antony, France), and pupillary rings, including the Perfect Pupil (Milvella Limited, North Sydney, NSW, Australia), the Graether 2000 pupil-expander system 
(Eagle Vision, Inc., Memphis, TN, USA), the Malyugin Ring ${ }^{\circledR}$ (MicroSurgical Technology, Redmond, WA, USA), and the Morcher pupil dilator (Morcher, Stuttgart, Germany). ${ }^{17,74-77}$

\section{Efficacy of phenylephrine and ketorolac on intraoperative mydriasis and postoperative pain control}

Phenylephrine is a selective alpha-1 adrenergic receptor agonist, which has mydriatic effects on the iris..$^{9,39,40}$ It has shown success both topically and intracamerally in maintaining mydriasis during cataract surgery. 9,10,29,70 Several concentrations of phenylephrine have been evaluated and several studies have shown an increase in effectiveness of pupil dilation with higher concentrations. ${ }^{10,40}$ However, other studies differ in their conclusions. One study found that $2.5 \%$ phenylephrine is as effective as $10 \%$ phenylephrine in the maintenance of mydriasis during both extracapsular and phacoemulsification cataract extraction when used in conjunction with cyclopentolate. ${ }^{78}$ Importantly, with the use of a lower concentration of phenylephrine, there is a lower risk of systemic side effects.

Phenylephrine has been combined with a number of other topical drops to evaluate improvements in dilation and maintenance of dilation during cataract surgery. Most commonly, phenylephrine is combined with tropicamide. The use of tropicamide $1.0 \%$ and phenylephrine $2.5 \%$ proved to be an effective preoperative regimen for mydriasis in phacoemulsification, and it showed improved dilation compared to lower concentrations of tropicamide $0.5 \%$ and phenylephrine $0.5 \%$ with equal safety profiles. ${ }^{8}$

Ketorolac has been approved in the US for treatment of postoperative pain and inflammation after cataract surgery. Ketorolac has been used successfully in the alleviation of ocular inflammation and pain, the prevention and treatment of postoperative cystoid macular edema, and the prevention of intraoperative miosis. ${ }^{7,79-80}$ Use of twice-daily ketorolac $0.45 \%$ for 16 days beginning 1 day before surgery resulted in a greater percentage of patients with an ocular inflammatory score of 0 on day 14 (52.5\% compared to $26.5 \%$ in the vehicle group) and a greater number of patients with a pain score of 0 on day 1 postoperatively $(72.4 \%$ versus $39.7 \%$, respectively). ${ }^{79}$ Topically, it is available in $0.4 \%, 0.5 \%$, and $0.45 \%$ concentrations (ACULAR LS ${ }^{\circledR}$, ACULAR $^{\circledR}$, and ACUVAIL $^{\circledR}$; Allergan, Inc., Irvine, CA, USA). It was first used at a concentration of $0.5 \%$ for the treatment of conjunctivitis and pain; however, lower concentrations have since become available, and the preservatives have also been changed to assist in patient comfort upon instillation. Ketorolac $0.45 \%$ was found to be superior in its ability to inhibit prostaglandin E2 compared to nepafenac $0.1 \%$ and bromfenac $0.09 \%$, which are used in patients undergoing phacoemulsification. Prostaglandin E2 is a mediator of inflammatory signals within the COX pathway and it can also enhance the constrictor action of the iris sphincter through mechanisms that are not dependent on cholinergic receptors. ${ }^{81-83}$ Ketorolac tromethamine $0.5 \%$ was also better than prednisolone acetate $1 \%$ solutions in preventing surgically-induced miosis. ${ }^{11}$

Given the success of these two medications with cataract surgery, the thought of combining the two for use in intraoperative administration was implemented. The two medications would work synergistically in the establishment and maintenance of pupillary dilation and would prevent/control postoperative pain and inflammation to improve patient comfort and satisfaction.

\section{Early research on ketorolacl phenylephrine or OMS302}

A number of the early clinical trials have reported success in the use of OMS302 in the maintenance of pupillary dilation during cataract surgery and in the prevention of postoperative pain and inflammation. ${ }^{84-87}$ In a Phase IIB study, 223 subjects undergoing cataract extraction with lens replacement were randomized to receive treatment with one of the following: balanced salt solution only (vehicle); phenylephrine; ketorolac; or OMS302. ${ }^{84}$

Results from this study were announced in 2011 by Omeros Corporation. They reported that OMS302 and phenylephrine demonstrated significant improvement in the maintenance of intraoperative mydriasis, compared with vehicle and ketorolac alone ( $P<0.00001$ for both comparisons $).{ }^{84}$ They found that pupil diameter steadily decreased throughout the surgical procedure in both the vehicle and ketorolac groups, and vehicle and ketorolac use resulted in pupillary constriction greater than $4 \mathrm{~mm}$ from baseline. More than 20\% of subjects in the vehicle-controlled group experienced a decrease in pupillary diameter of $2.5 \mathrm{~mm}$ or more during surgery. In contrast, only $4.4 \%$ of OMS302-treated subjects experienced this level of pupillary constriction. ${ }^{84}$

In addition, they found patients treated with OMS302 or ketorolac alone had significantly less pain in the early postoperative period than patients who received vehicle or phenylephrine alone ( $P<0.05$ for both comparisons). Moderate to severe pain was reported by $17 \%$ of vehicle-treated subjects. They reported that OMS302 was safe and well-tolerated by the patient population. ${ }^{84}$ 
In the first Phase III trial, including over 400 participants, Omeros reported that OMS302 demonstrated statistically significant superiority over placebo in the maintenance of intraoperative mydriasis and a reduction of postoperative pain (both $P<0.00001$ ). ${ }^{87}$

Safety data were collected until postoperative day 90 . The results from the first Phase III clinical trial were presented at the American Academy of Ophthalmology Meeting in Chicago, November 2012. ${ }^{89,90}$ It was a 405 -subject randomized, double-blind, and placebo-controlled study in which all patients received preoperative mydriatics and anesthetics. The investigators found that OMS302 was delivered intracamerally in balanced salt solution during the IOL replacement surgery. OMS302 was superior to placebo in maintaining mydriasis $(P<0.0001)$ and preventing pain $(P<0.0001)$. Fewer OMS302-treated subjects experienced a pupil diameter $<6 \mathrm{~mm}$ at cortical clean up $(P<0.0001)$ or moderate-to-severe pain $(P=0.006)$, and more patients were pain-free $(P=0.011)$. Adverse events were similar between the two groups. Therefore, their conclusion was that OMS302 significantly maintained mydriasis, prevented miosis, and decreased postoperative pain. ${ }^{90}$ Additionally, a second trial was designed and initiated to evaluate the same efficacy and safety measures as the earlier Phase IIB and Phase III clinical trials.$^{85}$ In November 2012, Omeros Corporation announced that OMS302 met the coprimary efficacy end points in this second pivotal Phase III clinical trial by demonstrating statistically significant differences in the maintenance of intraoperative mydriasis $(P<0.00001)$ and in the reduction of pain in the early postoperative period $(P=0.0002)$ between OMS302 and placebo. ${ }^{85,88}$ Pupil constriction of at least $3 \mathrm{~mm}$ was common in control patients, while constriction $>1 \mathrm{~mm}$ was uncommon in OMS302treated patients. Safety data were collected until postoperative day 90. OMS302 was reported to be well-tolerated in this Phase III clinical trial. ${ }^{85}$ The incidence of adverse events was similar between the two treatment groups. Additionally, the adverse event profile was comparable to those seen in prior OMS302 clinical trials. ${ }^{84,87}$

In November of 2013, the combined results of the two Phase III clinical trials (both including $>400$ participants) were presented as a scientific poster at the American Academy of Ophthalmology Annual Meeting in New Orleans. ${ }^{91}$ The results showed that OMS302 maintained a necessary pupil diameter throughout the IOL replacement procedure, while the placebo group showed progressive constriction $(P<0.00001)$. Fewer OMS302-treated patients $(<3 \%)$ compared to placebo-treated patients $(>27 \%)$ experienced $\geq 2.5 \mathrm{~mm}$ pupillary constriction, representing a $50 \%$ decrease in the operative field $(P<0.001)$ during the surgery. ${ }^{92}$ Larger randomized clinical trials are warranted to provide evidence of the safety profile and efficacy of this formulation, OMS302, of its goal of maintaining mydriasis and preventing pain associated with IOL replacement surgery.

\section{Current ongoing research on the medication Approvals in Europe and the US for use in ophthalmic surgery}

The US Food and Drug Administration (FDA) has accepted a proposed brand name for OMS302, Omidria ${ }^{\mathrm{TM}}$ (Omeros Corporation). The acceptance of the proprietary brand name by the FDA is subject to the agency's final determination prior to any approval of the product's new drug application and market launch, expected in 2014. Omeros Corporation previously provided the trademark application for Omidria $^{\mathrm{TM}}$ from the United States Patent and Trademark Office (Alexandria, VA, USA). The company also submitted the brand name, Omidria ${ }^{\mathrm{TM}}$, to the European Medicines Agency, with a decision anticipated soon. Omeros Corporation also recently registered Omidria ${ }^{\mathrm{TM}}$ as a European Community Trade Mark. Finally, Omeros Corporation has also received permission by the FDA to study OMS302 in the pediatric population undergoing primary cataract extraction, and the results will likely be available in the postmarketing period. ${ }^{93}$

\section{Clinical trials ongoing or completed}

There are four clinical trials ${ }^{84-87}$ listed in Clinicaltrials.gov (see Table 3). Omeros Corporation has recently presented the most currently available results at the American Academy of Ophthalmology Annual Meeting in 2013; ${ }^{91}$ however, the final official results and the report's submission to a peerreviewed journal are still pending.

\section{Conclusion}

Appropriate mydriasis and inflammatory control during intraocular lens exchange surgery is key to a successful surgical outcome., ${ }^{1,2}$ To achieve these, a myriad of topical and/or intracameral agents have been used to dilate the pupil and to control postoperative pain and inflammation, as we have reviewed. A prospective new therapy, OMS302, is a combination of ketorolac, an anti-inflammatory agent, and phenylephrine, a mydriatic agent. At this time, the available evidence in peer-reviewed literature for this new agent is limited. We believe larger studies testing the efficacy and 
Table 3 Clinical trials pending published results

\begin{tabular}{|c|c|c|c|c|}
\hline Clinical trial & Title & Phase & Status & Trial identifier \\
\hline I & $\begin{array}{l}\text { Safety, efficacy and pharmacokinetics of OMS302 in subjects } \\
\text { undergoing intraocular lens replacement with phacoemulsification } \\
(\text { OMS302-ILR-004) }\end{array}$ & III & $\begin{array}{l}\text { Completed, pending } \\
\text { published results }\end{array}$ & NCT0I579565 \\
\hline 2 & $\begin{array}{l}\text { Safety and efficacy of OMS302 in subjects undergoing intraocular } \\
\text { lens replacement with phacoemulsification (OMS302-ILR-003) }\end{array}$ & III & $\begin{array}{l}\text { Completed, pending } \\
\text { published results }\end{array}$ & NCT0I454063 \\
\hline 3 & $\begin{array}{l}\text { Exploratory study of OMS302 injection in subjects undergoing } \\
\text { unilateral cataract extraction by phacoemulsification }{ }^{87}\end{array}$ & $\mid / / I$ & $\begin{array}{l}\text { Completed, pending } \\
\text { published results }\end{array}$ & NCT00721695 \\
\hline 4 & $\begin{array}{l}\text { Safety and efficacy of OMS302 in subjects undergoing unilateral } \\
\text { cataract extraction with lens replacement (CELR) }\end{array}$ & II & $\begin{array}{l}\text { Completed, pending } \\
\text { published results }\end{array}$ & NCT0II93I27 \\
\hline
\end{tabular}

safety profile of this new formulation are warranted to provide more evidence that supports its use.

\section{Disclosure}

None of the authors have or have had any current or past financial interest, support, or research participation in Omeros Corporation. The authors report no conflicts of interest in this work.

\section{References}

1. Zanetti FR, Fulco EA, Chaves FR, da Costa Pinto AP, Arieta CE, Lira RP. Effect of preoperative use of topical prednisolone acetate, ketorolac tromethamine, nepafenac and placebo, on the maintenance of intraoperative mydriasis during cataract surgery: a randomized trial. Indian J Ophthalmol. 2012;60(4):277-281.

2. Donnefeld ED. Current Use of Non-steroidal Anti-inflammatory Drugs in the Treatment of Ocular Inflammation Related to Cataract Surgery. European Ophthalmic Review. 2012;6(3):173-177.

3. Rooks WH 2nd, Maloney PJ, Shott LD, et al. The analgesic and antiinflammatory profile of ketorolac and its tromethamine salt. Drugs Exp Clin Res. 1985;11(8):479-492.

4. Rooks WH 2nd. The pharmacologic activity of ketorolac tromethamine. Pharmacotherapy. 1990;10(6 Pt 2):30S-32S.

5. Heath P, Geiter CW. Use of phenylephrine hydrochloride, neosynephrine hydrochloride, in ophthalmology. Arch Ophthal. 1949; 41(2):172-177.

6. Meyer SM, Fraunfelder FT. 3. Phenylephrine hydrochloride. Ophthalmology. 1980;87(11):1177-1180.

7. Heier J, Cheetham JK, Degryse R, et al. Ketorolac tromethamine $0.5 \%$ ophthalmic solution in the treatment of moderate to severe ocular inflammation after cataract surgery: a randomized, vehicle-controlled clinical trial. Am J Ophthalmol. 1999;127(3):253-259.

8. Lam PT, Poon BT, Wu WK, Chi SC, Lam DS. Randomized clinical trial of the efficacy and safety of tropicamide and phenylephrine in preoperative mydriasis for phacoemulsification. Clin Experiment Ophthalmol. 2003;31(1):52-56.

9. Neuhaus RW, Hepler RS. Mydriatic effect of phenylephrine 10\% (aq) vs phenylephrine 2.5\% (aq). Ann Ophthalmol. 1980;12(10):1159-1160.

10. Duffin RM, Pettit TH, Straatsma BR. $2.5 \%$ v $10 \%$ phenylephrine in maintaining mydriasis during cataract surgery. Arch Ophthalmol. 1983; 101(12):1903-1906.

11. Suleiman YM, Krdoghli NF, Ahmad AJ. Comparison of ketorolac tromethamine and prednisolone acetate in preventing surgically induced miosis during cataract surgery. Sultan Qaboos Univ Med J. 2010;10(1):57-63.

12. Omeros.com [homepage on the Internet] Seattle, WA: Omeros Corporation. [cited 2014 Feb 6]. http://www.omeros.com/pipeline/ ophtha.htm. Accessed February 6, 2014.
13. American Academy of Ophthalmology Cataract and Anterior Segment Panel. Preferred Practice Pattern ${ }^{\circledR}$ Guidelines. Cataract in the Adult Eye. San Francisco, CA: American Academy of Ophthalmology; 2011. Available from: http://one.aao.org/preferred-practice-pattern/cataractin-adult-eye-ppp--october-2011. Accessed

14. Guell JL, Rodriguez-Arenas AF, Gris O, Malecaze F, Velasco F. Phacoemulsification of the crystalline lens and implantation of an intraocular lens for the correction of moderate and high myopia: fouryear follow up. J Cataract Refract Surg. 2003;29:34-38.

15. Fink AM, Gore C, Rosen ES. Refractive lensectomy for hyperopia. Ophthalmology. 2000;107(8):1540-1548.

16. Joseph J, Wang HS. Phacoemulsification with poorly dilated pupils. J Cataract Refract Surg. 1993;19(4):551-556.

17. Goldman JM, Karp CL. Adjunct devices for managing challenging cases in cataract surgery: capsular staining and ophthalmic viscosurgical devices. Curr Opin Ophthalmol. 2007;18(1):52-57.

18. Dada T, Sharma N, Vajpayee RB, Dada VK. Conversion from phacoemulsification to extracapsular cataract extraction: incidence, risk factors, and visual outcome. J Cataract Refract Surg. 1998;24(11): 1521-1524.

19. Porela-Tiihonen S, Kaarniranta K, Kokki H. Postoperative pain after cataract surgery. J Cataract Refract Surg. 2013;39(5):789-798.

20. Parsons C, Jones DS, Gorman SP. The intraocular lens: challenges in the prevention and therapy of infectious endophthalmitis and posterior capsular opacification. Expert Rev Med Devices. 2005;2(2):161-173.

21. Woodcock M, Shah S, Smith RJ. Recent advances in customising cataract surgery. BMJ. 2004;328(7431):92-96.

22. Congdon N, Vingerling JR, Klein BE, et al; Eye Diseases Prevalence Research Group. Prevalence of cataract and pseudophakia/aphakia among adults in the United States. Arch Ophthalmol. 2004;122(4):487-494.

23. Mamalis N, Brubaker J, Davis D, Espandar L, Werner L. Complications of foldable intraocular lenses requiring explantation or secondary intervention - 2007 survey update. J Cataract Refract Surg. 2008;34(9):1584-1591.

24. Leysen I, Bartholomeeusen E, Coeckelbergh T, Tassignon MJ. Surgical outcomes of intraocular lens exchange: five-year study. J Cataract Refract Surg. 2009;35(6):1013-1018.

25. Woodward MA, Randleman JB, Stulting RD. Dissatisfaction after multifocal intraocular lens implantation. J Cataract Refract Surg. 2009;35(6):992-997.

26. Galor A, Gonzalez M, Goldman D, O’Brien TP. Intraocular lens exchange surgery in dissatisfied patients with refractive intraocular lenses. J Cataract Refract Surg. 2009;35(10):1706-1710.

27. Jones JJ, Jones YJ, Jin GJ. Indications and outcomes of intraocular lens exchange during a recent 5-year period. Am J Ophthalmol. 2014;157(1):154-162.e1.

28. Hejny C, Edelhauser HF. Surgical pharmacology: intraocular solutions and drugs used for cataract surgery. In: Buratto L, Werner L, Zanini M, Apple D, editors. Phacoemulsification: Principle and Techniques. Thorofare, NJ: Slack; 2003:230-236.

29. Lundberg B, Behndig A. Intracameral mydriatics in phacoemulsification cataract surgery. J Cataract Refract Surg. 2003;29(12):2366-2371. 
30. Fraunfelder FT, Scafidi AF. Possible adverse effects from topical ocular 10\% phenylephrine. Am J Ophthalmol. 1978;85(4):447-453.

31. Oğüt MS, Bozkurt N, Ozek E, Birgen H, Kazokoğlú H, Oğüt M. Effects and side effects of mydriatic eyedrops in neonates. Eur $J$ Ophthalmol. 1996;6(2):192-196.

32. Colin J. The role of NSAIDs in the management of postoperative ophthalmic inflammation. Drugs. 2007;67(9):1291-1308.

33. Flach AJ, Dolan BJ, Donahue ME, Faktorovich EG, Gonzalez GA. Comparative effects of ketorolac $0.5 \%$ or diclofenac $0.1 \%$ ophthalmic solutions on inflammation after cataract surgery. Ophthalmology. 1998;105(9):1775-1779.

34. Roberts CW. Pretreatment with topical diclofenac sodium to decrease postoperative inflammation. Ophthalmology. 1996;103(4):636-639.

35. Simone JN, Whitacre MM. Effects of anti-inflammatory drugs following cataract extraction. Curr Opin Ophthalmol. 2001;12(1):63-67.

36. Solomon KD, Vroman DT, Barker D, Gehlken J. Comparison of ketorolac tromethamine $0.5 \%$ and rimexolone $1 \%$ to control inflammation after cataract extraction. Prospective randomized double-masked study. J Cataract Refract Surg. 2001;27(8):1232-1237.

37. Solomon KD, Cheetham JK, DeGryse R, Brint SF, Rosenthal A. Topical ketorolac tromethamine $0.5 \%$ ophthalmic solution in ocular inflammation after cataract surgery. Ophthalmology. 2001;108(2): 331-337.

38. O'Brien TP. Emerging guidelines for use of NSAID therapy to optimize cataract surgery patient care. Curr Med Res Opin. 2005;21(7): 1131-1137.

39. Smith RB, Read S, Oczypok PM. Mydriatic effect of phenylephrine. Eye Ear Nose Throat Mon. 1976;55(4):133-134.

40. Haddad NJ, Moyer NJ, Riley FC Jr. Mydriatic effect of phenylephrine hydrochloride. Am J Ophthalmol. 1970;70(5):729-733.

41. Vaughan RW. Ventricular arrhythmias after topical vasoconstrictors. Anesth Analg. 1973;52(2):161-165.

42. Wilensky JT, Woodward HJ. Acute systemic hypertension after conjunctival instillation of phenylephrine hydrochloride. Am J Ophthalmol. 1973;76(1):156-157.

43. Solosko D, Smith RB. Hypertension following 10 per cent phenylephrine ophthalmic. Anesthesiology. 1972;36(2):187-189.

44. Salminen L. Review: systemic absorption of topically applied ocular drugs in humans. J Ocul Pharmacol. 1990;6(3):243-249.

45. Park JH, Lee YC, Lee SY. The Comparison of Mydriatic Effect Between Two Drugs of Different Mechanism. Korean J Ophthalmol. 2009;23(1):40-42.

46. Akman A, Aydin P. Comparison of mydriatic efficacy of spray application and drop instillation of tropicamide 1\%. Eye (Lond). 1999; 13(Pt 5):653-655.

47. Narváez J, Kronberg BP, Park H, et al. Pupil dilation using a standard cataract surgery regimen alone or with atropine $1.0 \%$ pretreatment: prospective comparative evaluation. J Cataract Refract Surg. 2010;36(4):563-567.

48. Torrón C, Calvo P, Ruiz-Moreno O, Leciñena J, Pérez-Iñigo A. Use of a new ocular insert versus conventional mydriasis in cataract surgery. Biomed Res Int. 2013;2013:849349.

49. Duffin RM, Camras CB, Gardner SK, Pettit TH. Inhibitors of surgically induced miosis. Ophthalmology. 1982;89(8):966-979.

50. Schalnus R. Topical nonsteroidal anti-inflammatory therapy in ophthalmology. Ophthalmologica. 2003;217(2):89-98.

51. Amon M, Busin M. Loteprednol etabonate ophthalmic suspension 0.5 $\%$ : efficacy and safety for postoperative anti-inflammatory use. Int Ophthalmol. Oct 2012;32(5):507-517.

52. Cervantes-Coste G, Sánchez-Castro YG, Orozco-Carroll M, MendozaSchuster E, Velasco-Barona C. Inhibition of surgically induced miosis and prevention of postoperative macular edema with nepafenac. Clin Ophthalmol. 2009;3:219-226.

53. Stewart R, Grosserode R, Cheetham JK, Rosenthal A. Efficacy and safety profile of ketorolac $0.5 \%$ ophthalmic solution in the prevention of surgically induced miosis during cataract surgery. Clin Ther. 1999;21(4):723-732.
54. Lane SS, Modi SS, Lehmann RP, Holland EJ. Nepafenac ophthalmic suspension $0.1 \%$ for the prevention and treatment of ocular inflammation associated with cataract surgery. $J$ Cataract Refract Surg. 2007;33(1):53-58.

55. Gamache DA, Graff G, Brady MT, Spellman JM, Yanni JM. Nepafenac, a unique nonsteroidal prodrug with potential utility in the treatment of trauma-induced ocular inflammation: I. Assessment of anti-inflammatory efficacy. Inflammation. 2000;24(4):357-370.

56. Nardi M, Lobo C, Bereczki A, et al. Analgesic and anti-inflammatory effectiveness of nepafenac $0.1 \%$ for cataract surgery. Clin Ophthalmol. 2007;1(4):527-533.

57. Modi SS, Lehmann RP, Walters TR, et al. Once-daily nepafenac ophthalmic suspension $0.3 \%$ to prevent and treat ocular inflammation and pain after cataract surgery: phase 3 study. J Cataract Refract Surg. 2014;40(2):203-211.

58. Lundberg B, Behndig A. Separate and additive mydriatic effects of lidocaine hydrochloride, phenylephrine, and cyclopentolate after intracameral injection. $J$ Cataract Refract Surg. 2008;34(2): 280-283.

59. Lundberg B, Behndig A. Intracameral mydriatics in phacoemulsification surgery obviate the need for epinephrine irrigation. Acta Ophthalmol Scand. 2007;85(5):546-550.

60. Behndig A, Eriksson A. Evaluation of surgical performance with intracameral mydriatics in phacoemulsification surgery. Acta Ophthalmol Scand. 2004;82(2):144-147.

61. Johansson M, Lundberg B, Behndig A. Optical coherence tomography evaluation of macular edema after phacoemulsification surgery with intracameral mydriatics. J Cataract Refract Surg. 2007;33(8):1436-1441.

62. Nikeghbali A, Falavarjani KG, Kheirkhah A. Pupil dilation with intracameral lidocaine during phacoemulsification: Benefits for the patient and surgeon. Indian J Ophthalmol. 2008;56(1):63-64.

63. Cionni RJ, Barros MG, Kaufman AH, Osher RH. Cataract surgery without preoperative eyedrops. J Cataract Refract Surg. 2003;29(12): 2281-2283.

64. Malik A, Fletcher EC, Chong V, Dasan J. Local anesthesia for cataract surgery. J Cataract Refract Surg. 2010;36(1):133-152.

65. Zhao LQ, Zhu H, Zhao PQ, Wu QR, Hu YQ. Topical anesthesia versus regional anesthesia for cataract surgery: a meta-analysis of randomized controlled trials. Ophthalmology. 2012;119(4):659-667.

66. Westborg I, Mönestam E. Intracameral anesthesia for cataract surgery: a population-based study on patient satisfaction and outcome. Clin Ophthalmol. 2013;7:2063-2068.

67. Karalezli A, Borazan M, Akova YA. Intracameral triamcinolone acetonide to control postoperative inflammation following cataract surgery with phacoemulsification. Acta Ophthalmol. 2008;86(2): 183-187.

68. Wang B, Dong N, Xu B, Liu J, Xiao L. Efficacy and safety of intracameral triamcinolone acetonide to control postoperative inflammation after phacotrabeculectomy. J Cataract Refract Surg. 2013;39(11): 1691-1697.

69. Manvikar S, Allen D. Cataract surgery management in patients taking tamsulosin staged approach. J Cataract Refract Surg. 2006; 32(10):1611-1614.

70. Gurbaxani A, Packard R. Intracameral phenylephrine to prevent floppy iris syndrome during cataract surgery in patients on tamsulosin. Eye (Lond). 2007;21(3):331-332.

71. Masket S, Belani S. Combined preoperative topical atropine sulfate $1 \%$ and intracameral nonpreserved epinephrine hydrochloride 1:4000 [corrected] for management of intraoperative floppy-iris syndrome. $J$ Cataract Refract Surg. 2007;33(4):580-582.

72. Lorente R, de Rojas V, Vázquez de Parga P, et al. Intracameral phenylephrine $1.5 \%$ for prophylaxis against intraoperative floppy iris syndrome: prospective, randomized fellow eye study. Ophthalmology. 2012;119(10):2053-2058

73. Goldman JM, Karp CL. Adjunct devices for managing challenging cases in cataract surgery: pupil expansion and stabilization of the capsular bag. Curr Opin Ophthalmol. 2007;18(1):44-51. 
74. Goldberg I. Flexible iris retraction hooks. Aust N Z J Ophthalmol. 1997;23(4):357.

75. Novák J. Flexible iris hooks for phacoemulsification. J Cataract Refract Surg. 1997;23(6):828-831.

76. Akman A, Yilmaz G, Oto S, Akova YA. Comparison of various pupil dilatation methods for phacoemulsification in eyes with a small pupil secondary to pseudoexfoliation. Ophthalmology. 2004;111(9):1693-1698

77. Auffarth GU, Reuland AJ, Heger T, Völcker HE. Cataract surgery in eyes with iridoschisis using the Perfect Pupil iris extension system. $J$ Cataract Refract Surg. 2005;31(10):1877-1880.

78. Tanner V, Casswell AG. A comparative study of the efficacy of $2.5 \%$ phenylephrine and $10 \%$ phenylephrine in pre-operative mydriasis for routine cataract surgery. Eye (Lond). 1996;10(Pt 1):95-98.

79. Donnenfeld ED, Nichamin LD, Hardten DR, et al. Twice-daily, preservative-free ketorolac $0.45 \%$ for treatment of inflammation and pain after cataract surgery. Am J Ophthalmol. 2011;151(3):420-426.e1.

80. Gupta VP, Dhaliwal U, Prasad N. Ketorolac tromethamine in the maintenance of intraoperative mydriasis. Ophthalmic Surg Lasers. 1997;28(9):731-738.

81. Koay P. The emerging roles of topical non-steroidal anti-inflammatory agents in ophthalmology. Br J Ophthalmol. 1996;80(5):480-485.

82. Warner TD, Mitchell JA. Cyclooxygenases: new forms, new inhibitors, and lessons from the clinic. FASEB J. 2004;18(7):790-804.

83. Arshinoff SA, Opalinski YAV. The pharmacotherapy of cataract surgery. In: Yanoff M, Duker JS, editors. Ophthalmology. 3rd ed. St Louis (MO): Mosby Elsevier; 2008:434-440.

84. Omeros Corporation. Safety and efficacy of OMS302 in subjects undergoing unilateral cataract extraction with lens replacement (CELR). Available from: http://clinicaltrials.gov/ct2/show/study/NCT01193127. NLM identifier: NCT01193127. Accessed March 17, 2014.

85. Omeros Corporation. Safety, efficacy and pharmacokinetics of OMS302 in subjects undergoing intraocular lens replacement with phacoemulsification (OMS302-ILR-004). Available from: http:// clinicaltrials.gov/ct2/show/study/NCT01579565. NLM identifier: NCT01579565. Accessed March 17, 2014.

86. Omeros Corporation. Exploratory study of OMS302 injection in subjects undergoing unilateral cataract extraction by phacoemulsification. Available from: http://clinicaltrials.gov/ct2/show/study/NCT00721695. NLM identifier: NCT00721695. Accessed March 17, 2014.
87. Omeros Corporation. Safety and efficacy of OMS302 in subjects undergoing intraocular lens replacement with phacoemulsification (OMS302-ILR-003). Available from: http://clinicaltrials.gov/ct2/ show/study/NCT01454063. NLM identifier: NCT01454063. Accessed March 17, 2014.

88. Newswire P. Omeros announces positive OMS302 safety data in phase 3 clinical trial. [cited April 29, 2014]. Available from: http://www. prnewswire.com/news-releases/omeros-announces-positive-oms302safety-data-in-phase-3-clinical-trial-187854311.html. Accessed April 29, 2014.

89. Whitaker S, Crandall A, Demopulos G, Ng E, Rosenblatt M. A Phase 3 clinical trial of the drug product OMS302 delivered intracamerally in BSS during IOL replacement surgery. Poster 11. [press release]. American Academy of Ophthalmology; 2012 [November 11]. Available from: http://www.prnewswire.com/news-releases/omeros-to-presentdata-from-successful-oms302-phase-3-clinical-trial-at-the-americanacademy-of-ophthalmology-annual-meeting-177836051.html. Accessed May 5, 2014

90. Whitaker S, Crandall A, Demopulos G, Ng Edmund, Rosenblatt M. A Phase 3 clinical trial of the drug product OMS302 delivered intracamerally in BSS during IOL replacement surgery. Poster presented at: American Academy of Ophthalmology Annual Meeting; November 10-11; 2012; Chicago, IL. Available from: http://www.nxtbook.com/ tristar/aao/final_program2012/. Accessed May 10, 2014.

91. Whitaker S, Crandall A, Demopulos G, Ng E. Two Phase 3 Trials of OMS302 in Irrigation Solution for Maintenance of Mydriasis in IOL Replacement. Poster 29. [press release]. American Academy of Ophthalmology; 2013 [November 16]. Available from http://www. nxtbook.com/tristar/aao/final_program2013/index.php\#/212. Accessed May 10, 2014.

92. Whitaker S, Crandall A, Demopulos G, Ng E. Two Phase 3 trials of OMS302 in irrigation solution for maintenance of mydriasis in IOL replacement. Poster presented at: American Academy of Ophthalmology Annual Meeting; November 16-17; 2013; New Orleans, LA.

93. ONE ${ }^{\circledR}$ Network: The Ophthalmic News and Education Network; Omeros Corporation [webpage on the Internet]. FDA approves study of phenylephrine-ketorolac combo in children. San Francisco, CA: American Academy of Ophthalmology; 2013 [cited February 6, 2014]. Available from: http://one.aao.org/headline/fda-approves-study-ofphenylephrineketorolac-combo. Accessed February 6, 2014.
Clinical Ophthalmology

\section{Publish your work in this journal}

Clinical Ophthalmology is an international, peer-reviewed journal covering all subspecialties within ophthalmology. Key topics include: Optometry; Visual science; Pharmacology and drug therapy in eye diseases; Basic Sciences; Primary and Secondary eye care; Patient Safety and Quality of Care Improvements. This journal is indexed on Submit your manuscript here: http://www.dovepress.com/clinical-ophthalmology-journal

\section{Dovepress}

PubMed Central and CAS, and is the official journal of The Society of Clinical Ophthalmology (SCO). The manuscript management system is completely online and includes a very quick and fair peer-review system, which is all easy to use. Visit http://www.dovepress.com/ testimonials.php to read real quotes from published authors. 